\title{
EDUCAÇÃO MATEMÁTICA EM ESCOLAS DE SURDOS*
}

\author{
Bruna Fagundes Antunes Alberton \\ Lodenir Becker Karnopp
}

\section{Contextualização de Pesquisa}

Que discursos estão presentes no ensino de matemática para surdos, em escolas de educação bilíngue? Temos como objetivo analisar os discursos sobre educação matemática em documentos escolares de escolas de surdos do Ensino Fundamental, localizadas em Porto Alegre/RS. As escolas, nomeadas pelos símbolos matemáticos $\alpha$ (alfa), $\beta$ (beta) e $\gamma$ (gama), trabalham na perspectiva bilíngue para a educação de alunos surdos. Foram analisados os seguintes documentos, disponibilizados pelas escolas investigadas: (a) Projetos Político-Pedagógicos (PPP) das escolas $\alpha, \beta, \gamma$; (b) referenciais curriculares da Escola ; (c) planos de estudo da Escola $\beta$; (d) regimento da Escola $\alpha$.

O presente capítulo baseia-se numa pesquisa sobre educação matemática, a qual resultou em uma dissertação de mestrado (ALBERTON, 2015), situada no campo dos Estudos Surdos, em articulação aos Estudos Culturais e aos Estudos Foucaultianos. Reocupamo-nos, aqui, com determinados materiais analisados na referida pesquisa, em um movimento constante de escrita com "[...] pausas para planejar, anotar e avaliar os nossos movimentos; e para rever, ressignificar e olhar sob outros ângulos nossas perguntas e objetos" (MEYER; PARAísO, 2012, p. 17). Entendemos que a língua de sinais, o conhecimento de metodologias visuais para a educação de surdos e a convivência com a comunidade surda podem promover adequadamente a educação de surdos. Segundo Thoma (2012), a "importância de alunos surdos serem educados em espaços escolares onde haja outros surdos" ganha força porque auxilia o processo de aquisição da língua e do conhecimento. Na troca de experiências com seus pares, surgem novas possibilidades de exploração de outras formas de aprendizagem. Surdos com diferentes identidades se beneficiam da troca de experiências, agregando novas possibilidades de comunicação e conhecimentos.

*DOI - 10.29388/978-65-86678-60-4-0-f.49-68 
Em pesquisas e debates mais específicos sobre a escola são feitas análises sobre o currículo, as práticas docentes, metodologias e avaliação que problematizam a escola como "máquina-de-Estado" que opera pela repetição e atua no processo de subjetivação dos sujeitos escolares (GALLO, 2011, p. 216), produzindo modos de ver, ser e agir no mundo. Na educação de surdos, esse processo ocorre considerando-se a língua e a cultura surda, entretanto, a escola de surdos reverbera os mesmos princípios de produção, de esquadrinhamento e normalização dos sujeitos.

Nesse sentido, o currículo não é simplesmente uma seleção, organização e distribuição do conhecimento, mas um artefato cultural que contribui para a formação de determinados tipos de sujeitos, de acordo com a lógica que se pretende. Nas discussões sobre currículo escolar, os Estudos Culturais problematizam o que ensinamos, para que ensinamos, para quem ensinamos e quais produções queremos atingir com as práticas curriculares. Em pesquisa sobre currículo na educação de surdos, Morais e Lunardi-Lazzarin (2009, p. 25) escrevem que:

[...] o currículo das escolas de surdos traz consigo as relações de poder. Como a cultura vem 'colada' a esse dispositivo escolar, tais relações também são vislumbradas na escola de surdos, onde a cultura surda é construída e reconstruída e o currículo é permanentemente reinventado.

Ao articular os Estudos Surdos com os Estudos Culturais, entendemos que os aspectos culturais e políticos da comunidade surda emergem e contribuem para intensificar a noção de comunidade. Os Estudos Surdos defendem que as identidades e a cultura surda devem ser reconhecidas e valorizadas no currículo, através do uso da língua de sinais, de estratégias e metodologias visuais, desenvolvendo a aprendizagem dos alunos surdos. Muitas conquistas já estão sendo vivenciadas: a língua de sinais como forma de instrução; as legendas; a presença de intérpretes, entre outros, são avanços que proporcionaram às pessoas surdas acessibilidades dentro de ambientes escolares.

Quando pensamos em pesquisa, pensamos em busca, em esmiuçar perspectivas que mobilizam um conhecimento, bem como outras possibilidades de pensar e de produzir, outras formas de ensinar e aprender. Na pesquisa desenvolvida, as análises foram empreendidas a partir da noção de discurso desenvolvida por Michel Foucault (1996), para o qual o discurso 
constitui os objetos e sujeitos de que tratam, produz experiência e práticas. Assim, fazer uma análise de discursos requer olhar para os enunciados e as relações de poder-saber que constituem verdades. No caso da presente pesquisa, faculta-nos apreender quais os discursos curriculares da educação matemática são produzidos e produzem práticas. Segundo Foucault, "[...] o discurso não é simplesmente aquilo que traduz as lutas ou os sistemas de dominação, mas aquilo por que, pelo que se luta, o poder do qual nos queremos apoderar" (FOUCAULT, 1996, p. 10). Por intermédio da análise dos documentos escolares, buscamos analisar a forma como vem sendo proposta a educação matemática para surdos e os discursos curriculares que ocupam esses espaços. Dessa forma, as discussões e as reflexões em torno dos documentos podem suscitar outras possibilidades de ensino, conhecimento e aprendizagem, pois é a partir dos documentos escolares que a escola organiza e desenvolve as propostas curriculares.

\section{Educação Escolar Bilíngue para Surdos}

O reconhecimento linguístico e cultural necessário para a educação bilíngue para surdos foi concretizado com a assinatura da Lei da Libras (BRASIL, 2002). A educação bilíngue pressupõe a valorização da diferença surda e da experiência visual, as metodologias visuais, recursos e materiais bilíngues, entre outros aspectos. Assim, na educação bilíngue para surdos, a Libras e o ensino com base no visual são fatores que devem estar presentes em todas as disciplinas.

A educação bilíngue de surdos está marcada por traços da cultura surda, que precisam estar imersos nela, pois integram-na e são traços inseparáveis da educação bilíngue. Se a cultura surda não estiver inserida no ambiente educacional, os surdos dificilmente terão acesso à educação plena como lhes é de direito e acabam por abandonar a escola (BRASIL, 2014, p. 13).

Um intenso movimento, fomentado pela comunidade surda, em prol da educação bilíngue, busca priorizar a cultura surda e a educação de surdos em Libras. Na comunidade surda, os surdos têm a oportunidade de interagir, aprender e aprimorar a comunicação entre seus pares. Entende-se que a educação bilíngue propõe o uso da língua de sinais e da língua portuguesa 
escrita. Ao tratar de educação bilíngue para surdos, o Plano Nacional de Educação (PNE) prevê, em sua meta 4:

4.7) garantir a oferta de educação bilíngue, em Língua Brasileira de Sinais - LIBRAS como primeira língua e na modalidade escrita da Língua Portuguesa como segunda língua, aos (às) alunos (as) surdos e com deficiência auditiva de 0 (zero) a 17 (dezessete) anos, em escolas e classes bilíngues e em escolas inclusivas, nos termos do art. 22 do Decreto no 5.626, de 22 de dezembro de 2005, e dos arts. 24 e 30 da Convenção sobre os Direitos das Pessoas com Deficiência, bem como a adoção do Sistema Braille de leitura para cegos e surdos-cegos (BRASIL, 2014).

O Plano Nacional de Educação (2014-2024) apresenta a meta 4.7, que oferta educação bilíngue, em Libras, aos alunos surdos ou com deficiência auditiva, em escolas bilíngues e em escolas inclusivas. Ao relacionar o conceito de bilinguismo à educação de surdos, percebe-se que, para determinados grupos socioculturais, a educação bilíngue não é escolha, é necessidade: esse é o caso de pessoas surdas.

A educação bilíngue entrelaça grupos socioculturais na história, na língua, na política e nas artes. Skliar $(2009$, p. 7) defende a educação bilíngue a partir de uma questão política: "[...] o 'político' como construção histórica, cultural e social, e o 'político' entendido como as relações de poder e conhecimento que atravessam e delimitam a proposta e o processo educacional". Ao estabelecer um olhar mais atento sobre educação bilíngue para surdos, a perspectiva visual e a diferença surda desvelam que, as representações da comunidade surda, cultura surda e pedagogia surda, estão constituídas e diluídas dentro da proposta bilíngue de educação.

\section{Educação Matemática nas Escolas de Surdos}

Em diferentes povos, há diferentes formas de aprender, diferentes atitudes e diferentes modos de relacionar-se com o outro, de solucionar problemas e de buscar alternativas. Cada comunidade possui uma maneira própria de posicionar-se defronte a discrepantes problemas. O que é relevante para um povo, pode não ser importante para o outro. Surdos que vêm de diferentes culturas se beneficiam da troca de experiências e agregam novos 
conhecimentos dentro de outros grupos, conforme afirmam Knijnik et al. (2013, p. 26): “[...] as práticas matemáticas são entendidas não como um conjunto de conhecimentos que seria transmitido como uma 'bagagem', mas que estão constantemente reatualizando-se adquirindo novos significados, ou seja, são produtos e produtores da cultura".

A Etnomatemática tem um olhar cuidadoso sobre as diferenças, as experiências, as culturas, os comportamentos sociais e os significados resultantes das práticas dos sujeitos. Desenvolver um currículo que leve em consideração a cultura e identidade do grupo a que se destina é proteger e valorizar as marcas de identidade de tal comunidade (ALBERTON, 2015). Para a Etnomatemática, as questões culturais são essenciais para a construção de conhecimentos matemáticos. Assim, para os surdos, a língua de sinais e a cultura visual são os meios que possibilitam a construção de conhecimentos. No caso de outras deficiências, outros elementos terão que ser apurados para a mediação de conhecimentos. Os conceitos matemáticos estão inseridos no planejamento e na organização da nossa vida. Embora tenhamos influências da comunidade, da escola, da família e de todo o ambiente onde vivemos, o conhecimento da matemática é internalizado para calcular, gerenciar nossas agendas, organizar nossos horários e compromissos, por exemplo.

Também dialogamos com produções de Borges e Nogueira (2013) para pensar sobre a educação matemática e suas implicações na educação de surdos. Com esses autores, entendemos que o conhecimento matemático toma díspares formas para atender a diferentes necessidades. As pessoas apropriam-se de conteúdos matemáticos para realizar atividades que não são únicas da escola. Os conhecimentos matemáticos se concretizam também em atividades do dia a dia, como calcular um trajeto, tirar a medida para confeccionar uma roupa, planejar uma viagem, organizar agendas etc. Nesse sentido, todas as pessoas desenvolvem pensamentos e raciocínios matemáticos para desempenhar suas funções cotidianas.

O estudo de Etnomatemática mostra que as práticas culturais e sociais são produções que podem organizar os planejamentos em ambientes diferentes. O aluno busca desenvolver atividades matemáticas para a resolução de problemas, mas possui a necessidade de organizar tarefas fora do âmbito escolar, por exemplo, organização de horário e cálculos mentais. A Etnomatemática mostra que a aula de matemática trabalha utilizando o 
cotidiano e as práticas sociais como formas de mostrar ao aluno a relação de conteúdos e realidade.

O currículo se constitui como artefato cultural importante na construção do conhecimento e na valorização de identidades, pois nele a cultura de um povo pode ser inserida e trabalhada por meio de metodologias, teorias e objetivos mais apropriados para cada grupo. Os estudos da Etnomatemática têm contribuído para a articulação entre o currículo e as diferenças. Para a aproximação entre Etnomatemática e a educação matemática, entendemos que a Etnomatemática busca articular a cultura nas práticas escolares onde este campo é perceptível, como nas questões culturais e sociais, como Alberton (2015, p. 77) afirma: “[...] os estudos da etnomatemática muito têm contribuído para a articulação entre o currículo e as diferenças. Este campo de estudos mostra que diferentes grupos sociais podem adquirir conhecimento nos aspectos culturais da Matemática".

Alicerçadas nessas considerações, apresentamos a análise dos documentos escolares, o que nos leva a pensar sobre os discursos curriculares da educação matemática que hoje são produzidos nas escolas investigadas. Assim, apresentamos neste capítulo, os enunciados que produzem práticas de educação matemática nas escolas de surdos investigadas. Por meio da leitura dos documentos escolares, realizamos as análises, fazendo as marcações necessárias e organizando uma tabela com excertos recorrentemente encontrados. Primeiramente, vejamos as propostas de educação de surdos contidas nos documentos:

\footnotetext{
Considerando a LIBRAS como a língua materna dos surdos e elemento construtor de desenvolvimento cognitivo e de identidade surda, a partir da interação, da troca e da identificação com seus pares, o sujeito surdo se apropria do conhecimento, constrói sua identidade, desenvolvendo, de forma natural sua língua. De acordo com esta perspectiva, pretende-se garantir o direito linguístico, a valorização da cultura surda, entendendo a Língua de Sinais como a primeira língua do surdo, numa perspectiva bilíngue a qual trata como um direito daqueles que utilizam uma língua diferente da língua oficial de serem educados na sua própria língua.

Assim sendo, o bilinguismo pressupõe a Língua de Sinais como ferramenta fundamental para o ensino de todas as disciplinas, recebendo este status de primeira língua, a qual deve ser adquirida num contexto comunicacional natural, onde os diferentes sujeitos e interfaces que estão inseridos no contexto e estrutura escolar também fazem parte desta educação bilíngue assumindo um papel importante na difusão da Língua de Sinais. Neste contexto, a Língua Portuguesa escrita deverá ser ensinada como língua estrangeira, requerendo, necessariamente, o uso de metodologias específicas para a aprendizagem de segunda língua, sem esquecer,
} 
entretanto, que esta aprendizagem irá ocorrer a partir da competência na primeira língua LIBRAS (PPP, Escola $\alpha$, p. 16).

Considera-se a língua de sinais como a primeira língua do surdo e, portanto, parte-se do princípio de que este terá maior competência em sua primeira língua - LIBRAS - e que esta servirá como base para a aquisição da Língua Portuguesa. A aprendizagem de uma segunda língua se dá por meio da competência em outra, como acontece com os ouvintes, pois aprendem uma segunda língua tendo como base a língua natural. O objetivo da educação bilíngue é que o surdo alcance um desenvolvimento linguístico-cognitivo e que tenha acesso às duas línguas - a língua de sinais e a língua portuguesa em sua modalidade escrita. (SILVA, 2008) (PPP, Escola y, p. 12).

[a] proposta educacional prioriza o desenvolvimento da Língua de Sinais (L1) pelo contato das crianças com profissionais surdos e ouvintes usuários desta língua; a partir da Língua de Sinais, essas crianças são expostas ao ensino da escrita da Língua Portuguesa (L2). A educação bilíngue considera as particularidades e materialidade da Língua de Sinais e os aspectos culturais a ela associados, pressupondo que os educadores envolvidos no processo de ensino e aprendizagem tenham domínio da Língua Brasileira de Sinais (LIBRAS) e da Língua Portuguesa no que diz respeito ao funcionamento de cada uma delas em seus diferentes usos sociais.

Desse modo, os processos de ensino-aprendizagem desenvolvem procedimentos metodológicos específicos para o currículo que contempla a diversidade sociocultural e linguística dos educandos surdos e surdos com outras deficiências, tomando como base os estudos sobre ensino-aprendizagem de segunda língua (L2) (PPP, Escola $\beta$ está elaborando um novo projeto pedagógico).

As três escolas trabalham na perspectiva de uma educação bilíngue e atendem, especificamente, alunos surdos, respeitando e valorizando identidade e cultura surda na comunidade escolar. Os PPPs das escolas analisadas indicam possibilidades de ensino-aprendizagem considerando uma educação escolar bilíngue, por meio da língua de sinais e a língua portuguesa escrita.

A escola $\alpha$ está localizada na zona norte de Porto Alegre/RS, em prédio amplo e espaçoso, atende 99 alunos e possui uma equipe composta pela direção, supervisão, orientação educacional e psicóloga. Essa escola reconhece a comunidade surda, valoriza a língua de sinais, cultura e identidade dos alunos surdos. Segundo o PPP, em todas as áreas, reconhece ser valorizada a bagagem cultural do aluno para que se sinta acolhido e estimado. Assim, o 
processo ensino-aprendizagem propõe atividades com a recepção visoespacial, com ferramentas que tornem significativas a leitura, a escrita, exercícios e produções a partir de estímulos visuais, conforme excertos que seguem:

Nossa prática educacional baseia-se na exploração dos conhecimentos trazidos pelo aluno de acordo com o contexto em que está inserido, estando voltada para a construção dos conhecimentos partindo da realidade do educando.

[...] nossa metodologia prioriza a Língua de Sinais, mas também faz uma abordagem do letramento, reconhecendo que existe uma relação direta deste conceito como componente importante na construção do sujeito, estando diretamente ligada a uma natureza política, social, econômica, histórica e cultural, entendendo que o uso da leitura e escrita são importantes elementos de transformação social e individual no sujeito, consciente de sua realidade.

[...]

Sabendo que o processo de aprendizagem do sujeito surdo acontece de forma viso-espacial, nossa proposta busca, através de diferentes ferramentas pedagógicas, proporcionar elementos facilitadores deste processo.

Na prática, as ações pedagógicas são desenvolvidas através de atividades significativas, utilizando Língua de Sinais, ilustrações e escrita. Desta forma, a atuação em sala de aula aborda os assuntos em Língua de Sinais, estimula o visual, provoca discussão em Língua de Sinais, enfatiza o significado de novas palavras, ampliando o vocabulário, organiza o esquema principal, elabora o texto de acordo com a compreensão em cada faixa etária e realiza os exercícios a partir do material concreto (PPP, Escola $\alpha$, p. 24-25).

A escola $\beta$, que atende 92 alunos, oferece o Ensino Fundamental. É composta por uma equipe diretiva, supervisão, orientação e psicóloga, com um ambiente amplo e adequado a todas as atividades necessárias. Conta com uma sala para a realização de cursos, como teatro, artes, e também cursos de Libras. Outrossim, oferece recursos e serviços educacionais especiais como o Centro Social, Clínica Especializada em Comunicação, o Programa de Habilitação e Reabilitação e Estimulação Precoce, Programa de orientação familiar - Psicologia, Serviço Social, Otorrinolaringologia, Fonoaudiologia e Audiologia. Tendo como objetivo: "[...] garantir um currículo que possibilite a formação de cidadãos comprometidos com a defesa da vida, tornando os conteúdos significativos para a existência dos educandos e incentivar os educadores a manter uma formação continuada" (PPP, Escola $\beta$, p. 3). Por conseguinte, essa escola organiza e planeja ações para estimular o aluno a ser 
ativo e participante, atuante na transformação do mundo, conforme evidenciam os excertos que seguem:

O Currículo propõe flexibilidade e descentralização, reforçando a necessidade de construção de uma identidade coletiva em que as decisões e responsabilidades sejam compartilhadas em todos os níveis e modalidades de ensino, tendo como base o respeito aos direitos e deveres dos educandos, bem como aos/às professores/as e à comunidade escolar. No desenvolvimento do currículo a formação básica do cidadão, objetivo do ensino fundamental, deve estar articulada às áreas do conhecimento e às dimensões da vida cidadã, através dos temas transversais (PPP, Escola $\beta$ ).

A escola $\gamma$ oferece o Ensino Fundamental, nos Ciclos de Formação e Educação de Jovens e Adultos (EJA), com atendimento Educacional Especializado (AEE) e conta 56 alunos matriculados. Essa escola tem recursos para alunos surdos com outras deficiências, por exemplo, possui materiais indispensáveis de adaptação, rampas de acesso às salas de aulas e banheiros adaptados. Segundo o PPP da escola, sua proposta é garantir a aquisição da língua de sinais para garantir a escolarização do aluno.

A aquisição da linguagem em crianças surdas deve ser garantida através de uma língua visualespacial, através da LIBRAS. Se a criança chega na escola sem a aquisição da língua de sinais é fundamental que o trabalho seja direcionado para o processo de aquisição da mesma.

Garantir o acesso à língua de sinais é garantir a aquisição da linguagem, a aquisição de valores, culturas e padrões sociais que perpassam através do uso da língua. A criança surda precisa ter acesso à LIBRAS e interagir com várias pessoas que usam tal língua para constituir sua linguagem e formar sua identidade (PPP, Escola ү, p. 10-11).

Em uma perspectiva de educação bilíngue, os documentos de cada escola consideram cultura, identidade e diferença surdas como elementos de valorização e aprendizagem do aluno surdo. A escola $\alpha$ tem foco principal no aspecto visual em sala de aula; a escola $\beta$ discute sobre currículo e a identidade com uma prática pedagógica reflexiva, e a escola $\gamma$ foca na discussão sobre construção de identidades dos alunos surdos e aquisição de língua de sinais dos alunos surdos.

Ao analisarmos os documentos que abordam o currículo, nas três escolas, percebemos que todas buscam valorizar as identidades, a diferença e a cultura surda. Os documentos orientam os planejamentos e as práticas de 
educação matemática, buscando articular os conteúdos às experiências vivenciadas pelos alunos. Nesse sentido, os PPPs orientam que as questões da diferença no currículo, enfatizando a importância da língua de sinais e da cultura visual, estejam presentes na escola de surdos. O currículo escolar deve estar ancorado nas políticas educacionais que norteiam a educação de surdos para que sejam produzidos significados para eles. Para Alberton (2015, p. 74): "A Educação Matemática desenvolve habilidades para a manutenção da vida e, por isso, faz-se necessário um olhar atento sobre os conhecimentos que já fazem parte das experiências culturais dos alunos surdos [...]". As escolas de surdos elaboram suas propostas pedagógicas considerando que a cultura é fundamental para que os surdos façam as conexões necessárias para atingir uma compreensão clara do conteúdo, centrada na língua de sinais e na experiência visual dos surdos.

$\mathrm{Na}$ análise do PPP da escola $\gamma$, encontramos referência aos grupos sociais e culturais nas ações educativas. A cultura visual do surdo, trabalhada sem desvincular-se do contexto socioeconômico e cultural da comunidade surda, traz a realidade diária para o processo de ensino-aprendizagem. Para isso, são objetivos curriculares:

[...] garantir aos nove anos de escolarização básica do ensino fundamental um ensino qualificado, atualizado e consonante com as necessidades do mundo contemporâneo, sem estar desvinculado, em nenhum momento, do contexto sócio-econômico e cultural em que os alunos estão inseridos (REFERENCIAIS CURRICULARES, Escola $\gamma$, p. 5, grifos nossos).

A escola $\gamma$ coloca que o currículo trabalhado está associado aos aspectos culturais e sociais da comunidade surda. Nessa escola,

[..] o currículo é pensado em seu sentido mais abrangente, o qual insere as atividades teórico-práticas presentes na vida escolar e o processo de desenvolvimento da aprendizagem dentro e fora do espaço restrito da escola. Assim, quando falamos em currículo, estamos tocando na questão das ações e inter-relações que se estabelecem dentro da prática cultural e social, na qual a escola está inserida, e que são determinantes do processo de desenvolvimento dos sujeitos ali envolvidos (PPP, Escola $\gamma$, p. 10-11, grifos nossos).

Analisando o PPP da escola $\beta$, percebemos que os planejamentos nessa escola são pensados e organizados de forma que o currículo esteja 
vinculado ao contexto sociocultural, com atenção às experiências dos alunos para que estes façam parte do processo de ensino-aprendizagem. Nos documentos da escola $\beta$ encontramos referências sobre a educação de surdos e as suas identidades articuladas com as práticas pedagógicas. A escola mostra-se preocupada em acompanhar as rápidas mudanças do mundo contemporâneo e entende que as relações pedagógicas devem ser reflexivas e atentas às demandas dos sujeitos a que atende.

Para efetivar o desenvolvimento de competências e habilidades dentro do Ensino Fundamental para além do saber fazer, é necessário adotar um referencial metodológico que dê visibilidade ao currículo e uma identidade à prática pedagógica reflexiva. Dessa maneira, professores/as e educandos devem eleger o diálogo como eixo das relações e fundamento do ato de educar (PPP, Escola $\beta$, está elaborando um novo projeto pedagógico).

Vivenciamos, hoje, um período de mudanças, impregnado de novas ideias que estão apontando em direção a um conjunto de condições sociais, que estão reestruturando os mapas sociais e culturais desta época. Nesta perspectiva de reconstrução, reorganização e principalmente de reformulação, novos sujeitos se formam e se constituem, e junto com eles novas identidades e posições sociais (PPP, Escola $\beta$, p. 8, grifos nossos).

Os conteúdos escolares, definidos pelo currículo, refletem os significados, valores culturais e sociais que foram construídos, ao longo da história, no processo de interação do homem com o mundo natural e social. Esses conteúdos, quando associados às competências e habilidades que os educandos desenvolvem para transformá-los em conhecimento, podem ser expressos como um conjunto de "fazeres e saberes" possíveis, a partir da apropriação dos conteúdos trabalhados nas diferentes áreas do conhecimento (PPP, Escola $\beta$, grifos nossos).

Em um mundo globalizado, apressuradas mudanças forçam transformações nas esferas sociais. E isso também exerce influência na educação de surdos. Do isolamento à participação nas lutas e movimentos, os surdos paulatinamente ganharam visibilidade e, sua língua, destaque e disseminação. A partir da luta do movimento surdo, a escola de surdos assumiu a língua de sinais como língua de instrução e, consequentemente, numerosas áreas passaram por mudanças, priorizando a formação de sujeitos surdos mais preparados para viver no mundo de hoje, no qual assumem novas posições e ocupam espaços outrora a eles vedados. 
Os objetivos que constam nos documentos das escolas também buscam proporcionar aos alunos a compreensão do conhecimento de seus contextos sociais e culturais. Dentro desses contextos, perceber-se como sujeito, entender que papel ocupa na sociedade, estabelecer metas e buscar conquistá-las, saber relacionar-se com o outro, são propostas de ações desenvolvidas para adequar conteúdos e metodologias que desafiem e oportunizem socialização e crescimento pessoal.

Ao longo do ensino fundamental espera-se que o aluno consiga:

- Habituar-se ao estudo, atenção, responsabilidade e cooperação;

- conhecer, interpretar e utilizar corretamente a linguagem matemática;

- Adquirir conhecimentos básicos, a fim de possibilitar sua integração na sociedade em que vive [...] (REGIMENTO ESCOLAR, Escola $\alpha$, p. 31, grifo nosso).

- Ampliar e construir novos significados para os números (naturais, inteiros e racionais) a partir de sua utilização no contexto social e da análise de alguns problemas históricos que motivaram sua construção;

[...]

- Ampliar e construir noções de medida, pelo estudo de diferentes grandezas, a partir de sua utilização no contexto social e da análise de alguns dos problemas históricos que motivaram sua construção. [...]. (PLANOS DOS ESTUDOS, Escola $\beta$, grifos nossos).

- Aprender a linguagem matemática através do uso de dados e informações;

- Compreender o conhecimento matemático associado a situações socioetnoculturais; [...]. (REFERENCIAIS CURRICULARES, Escola $\gamma$, p. 22, grifo nosso).

Nos documentos das escolas vemos que os trabalhos com os conteúdos matemáticos podem ser entendidos a partir da Etnomatemática, uma vez que os planejamentos levam em consideração as experiências sociais e culturais.

Para refletir sobre a educação matemática e o ensino de surdos nos contextos sociais, vale lembrar que as pessoas surdas também têm direito à informação e acesso aos acontecimentos, para que possam construir seus próprios conceitos e opiniões. Segundo o PPP, a escola $\alpha$ visa ações para a diferença, a identidade e a cultura surda, conforme excerto a seguir: 
[...] buscamos uma pedagogia e um currículo que introduzam o significado de diferença, identidade e cultura tão necessária para a educação de surdos (PPP, Escola $\alpha$, p. 8).

Dessa maneira, utiliza-se e amplia-se o uso da língua de sinais, dando visibilidade a essa língua, dentro e fora da escola, com exercícios de diálogo e criatividade para desinibir e valorizar a identidade surda. Busca-se, então, construir espaços onde haja mais ações para o fortalecimento da cultura, onde o aluno possa produzir e compartilhar os valores dessa comunidade.

As adaptações de currículo no PPP da escola $\beta$, para alunos surdos com outras deficiências associadas à surdez, partem do princípio de que as diferenças são marcas de identidade dos alunos surdos e, como tal, devem ser contempladas nos planejamentos de forma a atenderem as necessidades educacionais de todos e de cada um dos alunos, conforme coloca:

As Adaptações Curriculares - quando o planejamento trimestral não contempla as necessidades educacionais do aluno, o professor organiza um planejamento individualizado com alterações de maior ou menor expressividade do currículo - podemos adaptar objetivos, conteúdos (sequenciando ou priorizando alguns conteúdos, incluindo novos ou suprimindo outros), metodologias, técnicas e estratégias de aprendizagem e avaliação. Essas adaptações curriculares pretendem beneficiar o desenvolvimento pessoal e social dos alunos (PPP, Escola $\beta$, grifos nossos).

O professor de Matemática precisa de formação docente para atuação no ensino de surdos. A partir da Libras, os conteúdos devem ser ensinados e, como bem colocam os autores Borges e Nogueira (2013, p. 52), o ensino de Matemática e os materiais manipuláveis são importantes para a compreensão dos conteúdos:

A exploração de materiais manipuláveis, por exemplo, é bem vista no ensino de Matemática, não como um momento de lazer, mas, sobretudo, de aprendizagem. O que devemos considerar ao adotar o uso destes materiais, é um planejamento de ensino que, acima de tudo, privilegie o ensino de Matemática como finalidade principal.

Muitos professores organizam recursos visuais na aula de matemática, conforme coloca o Relatório sobre a Política Linguística de Educação Bilíngue Língua Brasileira de Sinais e Língua Portuguesa: “[...] no contexto da educação 
bilíngue, professores criam seu próprio material didático bilíngue, a partir da inserção de ilustrações e da língua de sinais escrita, que permitem associação de desenhos com a língua, e, por conseguinte, que levam à aprendizagem de associações" (BRASIL, 2013, p. 14). Em ensino bilíngue, os artefatos visuais favorecem o aprendizado por meio da oposição entre as duas línguas. Conforme Alberton (2015, p. 80) infere que

Pensar em seleção de conteúdos no ensino da Matemática é pensar em mecanismos que contribuam para o desenvolvimento intelectual e criativo do aluno. Planejar atividades desafiadoras, que coloquem o raciocínio articulado com a solução de problemas práticos, desperta a curiosidade e amplia o leque de soluções para um determinado problema. As questões matemáticas contribuem para a solução de problemas práticos da vida [...].

Borges (2006, p. 55), em pesquisa sobre educação matemática para surdos, realizou entrevista com um professor sobre os conteúdos trabalhados com esses alunos. $O$ professor entrevistado disse que:

[...] existe um acompanhamento mais próximo dos conteúdos a serem trabalhados nas aulas no ensino de ouvintes e [...], na educação de surdos, os professores têm maior liberdade de decisão na escolha dos temas a serem trabalhados. A única consideração feita por todos os estabelecimentos é uma atenção maior na preparação para os exames vestibulares.

A análise dos documentos escolares revela que o planejamento sobre conteúdos a serem trabalhados na escola de surdos é forjado sob flexível estrutura. Por entender que o professor conhece seu aluno surdo, sabe a quem interessa essa aprendizagem, a escola deixa-o mais livre para determinar o que ensinar. E, muitas vezes, a possibilidade de flexibilização traz desafios perante os quais escolhas devem ser feitas. Nesse aspecto, desafiadoras podem ser a organização, seleção e construção de materiais bilíngues para o ensino, uma vez que demandam conhecimento específico na área e disponibilidade para o planejamento e construção de materiais bilíngues e acessíveis. Nesse sentido, Sales $(2013$, p. 3) argumenta que: 
Os conteúdos curriculares podem ser os mesmos, mas a forma e o método de ensinar devem ser diferentes, visando a aprimorar o desenvolvimento das habilidades do indivíduo, pois, de acordo com suas necessidades, será necessário aplicar métodos de ensino particulares e específicos.

Entendemos que a escola tem como propósito preparar o aluno para as diferentes atividades sociais e de trabalho. Essas questões, em geral, estão presentes em debates e planejamentos das atividades escolares e são atendidas de acordo com a proposta do PPP da instituição de ensino. Todo o professor, assim, faz seu planejamento de atividades de acordo com os objetivos de cada escola e do perfil do aluno. As questões "o que ensinar?" e "para quem ensinar?" devem ser indagações recorrentes no planejamento de aulas.

\section{Considerações Finais}

O Ensino de Matemática, consoante os Projetos Político-Pedagógicos das três escolas aqui analisados, tem como objetivo estabelecer propostas de diretrizes e ações, organizando projetos e eventos que contemplem a educação de surdos. Desenvolver atividades que considerem as diferenças culturais e as identidades exige transformação no modo de cada professor, de planejar e ensinar. Os conteúdos são os mesmos propostos pelo currículo do nível de ensino, mas as estratégias terão que ser pensadas para o aluno surdo. Não temos uma cartilha que trace proposta e resultados, o caminho é do estudo e da pesquisa. Enquanto isso, vamos conversando, discutindo e trocando experiências.

Na pesquisa desenvolvida, observamos que as propostas apresentadas nos PPP dispõem sobre os conteúdos curriculares da área da Matemática: que sejam trabalhados valorizando os "conteúdos dentro de contextos sociais e culturais". As análises também sugerem que a metodologia e a avaliação do aluno surdo são feitas a partir de uma perspectiva de educação bilíngue, sendo o ensino oferecido através da Língua Brasileira de Sinais e da Língua Portuguesa. A proposta é que a metodologia e avaliação, associadas às questões culturais dos sujeitos a que se destinam, promovam o desenvolvimento de conhecimentos de Matemática. Entende-se que a escola 
de surdos também enfrenta o desafio de uma realidade áspera, pela condição social do aluno surdo.

Analisando os documentos das escolas $\alpha, \beta$ e $\gamma$, entendemos que as três escolas constroem suas práticas observando a diferença, a cultura e as identidades dos alunos surdos. Os professores de Matemática dessas escolas são orientados a planejar e organizar conteúdos articulados aos contextos sociais e culturais, em uma perspectiva de Etnomatemática. Os documentos sugerem que é possível os alunos terem uma vivência matemática dentro da cultura e da comunidade a que pertencem.

É essencial que as escolas proporcionem debates entre seus professores, de modo que as discussões sobre as práticas e as experiências pedagógicas sejam compartilhadas, e que atividades que promovam reflexões sejam desafios constantes. Nessa troca, a escola pode estabelecer diretrizes e ações organizando as atividades e os projetos a serem desenvolvidos por cada uma.

Percebemos que as três escolas fazem as discussões sobre ensino antes de estabelecer ações e organizam seus trabalhos considerando a luta política, legitimando a Libras e os anseios da comunidade surda. A análise dos documentos das escolas $\alpha, \beta$ e $\gamma$ mostram que as três instituições vêm construindo as propostas e trabalhos pedagógicos de acordo com as lutas políticas que advêm dos movimentos surdos, preservando e produzindo espaços de valorização da cultura surda. Assim, a cultura e as identidades surdas são pilares fundantes na construção da educação matemática para surdos.

Ainda, com todo o envolvimento da escola e de seus professores, reconhecemos que devemos perseguir mais resultados na educação, sendo tal busca o norte orientador de nossa pesquisa. É necessário promover debates, discutir experiências, buscar possibilidades que sejam desafiadoras para a permanência e qualificação do aluno; onde o aluno surdo adquira conhecimento, conquiste acolhimento e valorização da língua.

Ao concluir, reconhecemos a existência, nas escolas pesquisadas, do enaltecimento da cultura e da comunidade surda, por meio da inserção da Libras em todos os espaços escolares, com metodologias e estratégias em consonância com a cultura surda. 


\section{Referências}

ALBERTON, Bruna Fagundes Antunes. Discursos Curriculares sobre Educação Matemática para surdos. Porto Alegre: UFRGS, 2015. 107 f. Dissertação (Mestrado em Educação) - Programa de Pós-Graduação em Educação, Faculdade de Educação, Universidade Federal do Rio Grande do Sul, Porto Alegre, 2015.

BORGES, Fábio Alexandre. Institucionalização (sistemática) das representações sociais sobre a "deficiência" e a surdez: relações com o ensino de Ciências/Matemática. Maringá: UEM, 2006. 164 f. Dissertação (Mestrado em Educação) - Programa de Pós-Graduação em Educação para a Ciência e a Matemática, Faculdade de Educação, Universidade Estadual de Maringá, Maringá, 2006.

BORGES, Fábio Alexandre; NOGUEIRA, Clélia Maria Ignatius. Uma Panorama da inclusão de Estudantes Surdos nas aulas de Matemática. In: NOGUEIRA, Clélia Maria Ignatius (Org.). Surdez, inclusão e matemática. Curitiba: Editora CRV, 2013. p. 43-70.

BRASIL. Lei n. 10.436, de 24 de abril de 2002. Dispõe sobre a Língua Brasileira de Sinais - Libras e dá outras providências. Diário Oficial da União, Brasília, 2002. Disponível em:

http://www.planalto.gov.br/ccivil_03/leis/2002/I10436.htm. Acesso em: 13 jul. 2020.

BRASIL. Ministério da Educação. Secretaria de Educação Continuada, Alfabetização, Diversidade e Inclusão. Relatório do Grupo de Trabalho designado pelas Portarias no 1.060/2013 e no 91/2013: subsídios para a Política Linguística de Educação Bilíngue - Língua Brasileira de Sinais e Língua Portuguesa - a ser implementada no Brasil. Brasília, 2013. Disponível em: http://www.bibliotecadigital.unicamp.br/document/?code=56513. Acesso em: 13 jul. 2020. 
BRASIL. Lei no 13.005, de 25 de junho de 2014, que aprova o Plano Nacional de Educação e dá outras providências. Diário Oficial da União, Brasília, DF, Câmara dos Deputados, 2014. Edição extra. Disponível em:

http://www.planalto.gov.br/ccivil_03/_Ato2011-2014/2014/Lei/L13005.htm. Acesso em: 13 jul. 2020.

FOUCAULT, Michel. A ordem do discurso. 3. ed. São Paulo: Editora Loyola, 1996. p. 5-20.

GALLO, Silvio. Sob o signo da diferença: em torno de uma educação para a singularidade. In: SILVEIRA, Rosa Maria Hessel (Org.). Cultura, poder e educação: um debate sobre estudos culturais em educação. 2. ed. Canoas: Editora da ULBRA, 2011. p. 213-223.

KNIJNIK, Gelsa et al. Etnomatemática em movimento. 2. ed. Belo Horizonte: Autêntica Editora, 2013.

MEYER, Dagmar Estermann; PARAÍSO, Marlucy Alves. Metodologias de pesquisas pós-críticas ou Sobre como fazemos nossas investigações. In: EYER, Dagmar Estermann; PARAísO, Marlucy Alves (Org.). Metodologias de pesquisas pós-críticas em educação. Belo Horizonte: Mazza Edições, 2012. p. 15-22.

MORAIS, Mônica Zavacki de; LUNARDI-LAZZARIN, Márcia Lisa. Pedagogia e Diferença: capturas e resistências nos discursos curriculares da educação de surdos. In: THOMA, Adriana da Silva; KLEIN, Madalena (Org.). Currículo e avaliação: a diferença surda na escola. Santa Cruz do Sul: EDUNISC, 2009. p. 16-31.

SALES, Elielson Ribeiro de. A visualização no ensino de matemática: uma experiência com estudantes surdos. In: ENCONTRO NACIONAL DE EDUCAÇÃO MATEMÁTICA (ENEM), 11., 2013, Curitiba. Anais... Curitiba, 2013. Disponível em:

http://sbem.iuri0094.hospedagemdesites.ws/anais/XIENEM/pdf/80_28_ID.pdf Acesso em: 07 jul. 2020. 
SKLIAR, Carlos. A localização política da educação bilíngue para surdos. In: SKLIAR, Carlos (Org.). Atualidade da educação bilíngue para surdos. 3. ed. Porto Alegre: Mediação, 2009.

THOMA, Adriana da Silva. A afirmação da diferença e da cultura surda no cenário da educação inclusiva: desafios para o currículo. In: SARAIVA, Karla; MARCELLO, Fabiana de Amorim. (Org.). Estudos Culturais e Educação: desafios atuais. 1. ed. Canoas: Editora da ULBRA, 2012. p. 205-215.

\section{Documentos Analisados}

PLANOS dos Estudos. Escola $\beta$. Porto Alegre, RS.

PPP. Projeto Político Pedagógico. Escola a. Projetos Político-Pedagógicos da escola de Ensino Fundamental. Porto Alegre, RS.

PPP. Projeto Político Pedagógico. Escola $\beta$. Projetos Político-Pedagógicos da escola de Ensino Fundamental. Porto Alegre, RS.

PPP. Projeto Político Pedagógico. Escola y. Projetos Político-Pedagógicos da escola de Ensino Fundamental. Porto Alegre, RS.

REFERENCIAIS Curriculares. Escola $ү$. Porto Alegre, RS.

REGIMENTO Escolar. Escola $\alpha$. Porto Alegre, RS.

O presente trabalho foi realizado com apoio do Conselho Nacional de Desenvolvimento Científico e Tecnológico (Chamada MCTIC / CNPqNo 28/2018). 